\title{
O DIREITO INTERNACIONAL EM SUA APLICAÇÃO POR CORTES E TRIBUNAIS: RUMO A UM SISTEMA JUDICIAL INTERNACIONAL?
}

\section{EL DERECHO INTERNACIONAL EN SU APLICACIÓN POR LAS CORTES Y TRIBUNALES: HACIA UN SISTEMA JUDICIAL INTERNACIONAL?}

Camilla Capucio*

Resumo: Partindo da análise do direito internacional como um sistema, coeso e unitário, em negação ao discurso da fragmentação, este trabalho objetiva destacar a aplicação deste corpus juris na atualidade. Assim, são visitados não somente os tribunais e cortes internacionais, mas inclusive os órgãos judiciais internos. Por fim, é brevemente comentada a integração entre essas instituições, de modo a constituírem um sistema judicial internacional.

Resumen: A partir del análisis del derecho internacional como un sistema, con cohesión y unidad, en negación de la fragmentación, el presente trabajo pretende destacar la aplicación de este corpus juris. Así, se visitan no solo las cortes y tribunales internacionales, también se incluyen los órganos judiciales internos. Finalmente, se comenta la integración entre estas instituciones, a fin de formar un sistema judicial internacional.

Palavras-chave: Sistema jurídico internacional, Cortes e tribunais internacionais, Sistema judicial internacional

Palabras clave: Sistema jurídico internacional, Cortes y tribunales internacionales, Sistema judicial internacional

\section{INTRODUÇÃO}

O internacionalista é talvez o único dos juristas que tem uma tarefa constante: comprovar, de início, que o Direito Internacional existe, e é de fato "Direito". A necessidade de esclarecer a existência e juridicidade de

\footnotetext{
* Doutoranda em Direito Internacional pela USP. Mestre em Direito pela UFMG. Professora do Centro Universitário UNA, e de cursos de pós graduação. Pesquisadora do Núcleo de Estudos em Tribunais Internacionais (NETI-USP). Membro da Academia Brasileira de Direito Internacional (ABDI) e Associada Honorária do Instituto de Comércio Internacional do Brasil (ICI-BR). Advogada.
} 
seu objeto de estudo é resultado da propagação de uma clássica postura acadêmica de ceticismo face ao Direito Internacional, acompanhada pela tentativa errônea de se aplicar a esta disciplina os conceitos e estruturas do direito interno. A ausência de força coercitiva central, a identidade entre os sujeitos criadores e destinatários das normas, e a existência de descumprimentos por alguns Estados estampados nas manchetes dos jornais são os principais argumentos postos com frequência ao internacionalista pelos incrédulos no fenômeno jurídico internacional.

As transformações observadas nas últimas décadas e suas consequências, contudo, tornaram a postura de negação da existência e juridicidade do Direito Internacional minoritária e insustentável. Processos e eventos como a globalização/mundialização, a criação de Organizações Internacionais -principalmente da ONU, a internacionalização dos direitos humanos, a construção do sistema multilateral de comércio e a influência do Direito Internacional em todos os ramos do direito interno, são exemplos do escancaro do Direito Internacional e sua onipresença em todos os níveis das sociedades.

Entretanto, esses mesmos processos e eventos que demonstram a institucionalização, o fortalecimento, e a expansão do Direito Internacional trouxeram fenômenos como a sua especialização e a jurisdicionalização, que contemporaneamente levam alguns acadêmicos a duvidarem da unidade e coerência do Direito Internacional e, portanto, de sua configuração como um sistema. O discurso da fragmentação do Direito Internacional, tão difundido e presente na atualidade, tem inerente em si a ideia de ruptura e enfraquecimento da ordem jurídica internacional, e portanto, passa a ser a nova postura cética que deve ser enfrentada academicamente pelo internacionalista, enquanto crente na existência, juridicidade, coerência, e unidade do Direito Internacional, e em sua prevalência como instrumento de apaziguamento das relações sociais e inter-sociais e de construção de uma nova realidade.

Os aparentes argumentos anteriormente contrários à existência e juridicidade do Direito Internacional demonstraram características próprias de uma ordem jurídica ímpar, na qual os seus sujeitos tem a oportunidade de construir as normas às quais estarão submetidos. No mesmo sentido, conforme será melhor explicitado, os aparentes argumentos da fragmentação evidenciam a existência de um sistema jurídico único e coeso, embora não por isso seja acabado, perfeito ou insusceptível de incongruências.

É este o contexto deste trabalho, que se desenvolve em quatro partes principais, que buscarão suscintamente explicitar: (i) a defesa do Direito Internacional como um sistema, (ii) a relevância das Cortes e Tribunais Internacionais neste sistema; (iii) a relevância dos tribunais nacionais para o sistema jurídico internacional; e (iv) a crença na construção de um sistema jurisdicional internacional. 


\section{O DIREITO INTERNACIONAL COMO SISTEMA EM SUA} UNIDADE E COERÊNCIA

A temática da reflexão do sistema jurídico -e por conseguinte do Direito Internacional como sistema- envolve a escolha de marcos teóricos fundantes das discussões que se seguirão. $\mathrm{O}$ conceito de sistema, pois, e sua aplicação ao Direito Internacional serão abordados sob a perspectiva de certos autores paradigmáticos para a ciência jurídica, que elaboraram cada qual um conjunto de significados, não necessariamente coincidente com aquele conferido por outros autores não trabalhados neste artigo.

Em estudos sobre a história semântica do termo sistema, Mário G. Losano explicita que no grego clássico o termo tinha seus diversos significados conectados à ideia de agregação, e por isso usado em referência à ordem do mundo, seja ela ligada à sociedade ou ao cosmos ${ }^{1}$. Esse termo abstrato foi posteriormente recepcionado com dificuldades pelo latim, língua inclinada ao concreto, que tendeu a substituir o termo dos textos gregos por metáforas originadas da arquitetura e explicitadas pelos termos construere e structura. É essa a explicação, segundo o autor, para o entrelaçamento do significado semântico dos termos sistema e estrutura, que embora com particularidades, tem a função de designar uma natural tendência do jurista, que concebe sua disciplina como uma totalidade sistemática, ligada à ordem e harmonia ${ }^{2}$.

Assim,

(...) esses termos não são usados simultaneamente em todas as línguas, mas tiveram diversos êxitos: são as facetas historicamente condicionadas de um componente constante do pensamento humano, principalmente ocidental, em geral, e do pensamento jurídico em particular ${ }^{3}$.

A presença dessa tentativa de sistematização passou evolutivamente de uma preocupação intuitiva a um desenvolvimento teórico e técnico desencadeado pelo pensamento de filósofos e, posteriormente, de juristas. Apresentamos algumas concepções diversas de sistema jurídico, com o objetivo de elucidar questões relativas ao Direito Internacional como um sistema propriamente dito.

Em seu curso geral da Academia da Direito Internacional de Haia, George Abi-Saab esclarece que a conceituação dos sistemas e dos ordenamentos jurídicos, a prescindir do foco na norma em si, é reação face às teorias de Jonh Austin e da escola alemã, resultantes do

1 LOSANO Mario G. (2008) Sistema e estrutura no direito, volume I: das origens à escola histórica. São Paulo: Editora WMF Martins Fontes. p. 3.

2 LOSANO Mario G., Ibíd., p. 4, 23.

3 LOSANO Mario G., Ibíd., p. 5. 
endeusamento do Estado, e que priorizaram a sanção como definição do Direito, tendo como consequência a negação radical da existência do Direito Internacional como Direito. Para Austin, o Direito Internacional se tratava de uma "moralidade positiva", enquanto a escola alemã o interpretava como um braço ou ramo do direito interno, à semelhança do direito internacional privado. Assim, as teorias (i) da escola normativista (Kelsen); (ii) da escola institucionalista (Renaud, Romano); e (iii) da escola de Oxford (Hart), seriam reações àquele entendimento, e tentativas de analisar as facetas da noção de ordenamento e sistema jurídico ${ }^{4}$.

A teoria pura do direito de Hans Kelsen se propunha a eliminar do direito os elementos não jurídicos e a abstrair a estrutura das normas de seu conteúdo substancial, para estuda-las como partes articuladas do ordenamento jurídico. Segundo Kelsen, a validade da norma se relaciona ao pertencimento e coerência da norma com o ordenamento jurídico. $\mathrm{O}$ autor traçou uma estrutura piramidal para retratar o ordenamento jurídico, na qual as normas inferiores buscam sua condição de validade e existência nas normas superiores, o que culmina na norma fundamental ${ }^{5}$. A grundnorm seria, pois, a base ideológica de legitimidade e aceitação social do ordenamento jurídico, mas em sendo uma norma hipotética, se coloca como um recurso lógico para conferir completude e fechamento ao sistema jurídico analisado em abstrato.

No entendimento de Santi Romano, por sua vez, a essência do Direito não estaria na norma, mas em suas instituições, pois a primeira seria incapaz de explicar a unidade e identidade própria do sistema em si, e as últimas seriam capazes de dar efeito às primeiras. Somente as instituições confeririam ao sistema jurídico a objetividade e a sanção, características distintivas do Direito, segundo o autor, e das quais a norma individualmente seria esvaziada. O Direito e as instituições seriam, pois, manifestação ou expressão da realidade e da unidade de um corpo social, e a ordem social e a ordem jurídica seriam ambas dimensões da mesma sociedade ${ }^{6}$. Embora reconheça o valor de sua perspectiva holística, focada na relação entre sociedade e sistema jurídico, Georges Abi-Saab critica a minimização excessiva do papel da norma no ordenamento jurídico na perspectiva de Romano, vez que seriam elas garantidoras da própria coerência e integração lógica do sistema, bem como do arcabouço institucional ${ }^{7}$.

A teoria de Hart, por sua vez, oferece uma terceira concepção de sistema jurídico: um conjunto composto por regras primárias e regras secundárias. As regras primárias prescrevem comportamentos, as

4 ABI-SAAB George (1987) Cours Général de Droit International Public. Recueil des Cours. Collected Courses of the Hague Academy of International Law, Vol. 207. p. 107.

5 KELSEN Hans (2006) Teoria pura do direito. São Paulo: Editora WMF Martins Fontes, passim 6 ROMANO Santi (2008) O ordenamento jurídico. Florianópolis: Boiteux, passim.

7 ABI-SAAB George, Op. cit., p. 107. 
regras secundárias regem a estrutura, função e modalidades das regras primárias e de organização do próprio sistema. As regras secundárias se dividem em (a) regras de reconhecimento, pelas quais o sistema jurídico reconhece aquelas regras que lhe pertencem; (b) regras de mudança, que tratam do nascimento, modificação e desaparecimento das regras; e (c) regras de adjudicação, que tratam da aplicação de regras gerais a situações concretas e das sanções ${ }^{8}$.

Por fim, trazemos à discussão a perspectiva de Norberto Bobbio sobre o ordenamento jurídico, que em muito influencia a ciência jurídica contemporânea, e se apresenta como tentativa de releitura da teoria de Kelsen, inegavelmente influenciada pelo pensamento de Romano, e projetada para além da concepção de Hart.

Se inicialmente Bobbio dá um passo atrás ao conceituar o ordenamento jurídico simplesmente como "um conjunto de normas", que pressuporia como única condição a existência de mais de uma norma, o autor vai além ao analisar os elementos que conectam essas normas participantes do sistema entre si. Terá espaço, portanto, em sua visão, as facetas da (a) unidade; (b) coerência e (c) completude do sistema.

Assim, um ordenamento normativo se apresenta como unitário quando deriva de fontes, que por sua vez emanam do mesmo núcleo justificador dessas normas, a norma fundamental à qual todas as fontes podem ser remontadas. Sendo somente unitário, o ordenamento jurídico não se caracterizaria propriamente como sistema, pois esse pressupõe adicionalmente a coerência, para que resulte em uma "unidade sistemática" ${ }^{10}$. E assim explana Bobbio:

Entendemos por sistema uma totalidade ordenada, um conjunto de entes entre os quais existe uma certa ordem.Para que se possa falar de uma ordem, é necessário que os entes que a constituem não estejam somente em relacionamento de coerência entre si. Quando nos perguntamos se um ordenamento constitui um sistema, nos perguntamos se as normas que o compõem estão num relacionamento de coerência entre si, e em que condições é possível essa relação ${ }^{11}$.

O autor toma, pois, o sentido de sistema como um todo no qual não podem existir normas incompatíveis. A coerência deriva não da inexistência fática de conflito entre as normas, mas da eleição de critérios para a solução dessas antinomias, de modo a manter a justiça

8 HART H. L. A (2009) O Conceito de Direito. São Paulo: Editora WMF Martins Fontes, passim. 9 BOBBIO Norberto (1995) Teoria do Ordenamento Jurídico. Brasília: Editora Universidade de Brasília, p. 31.

10 BOBBIO Norberto, Ibíd., p. 71.

11 Ibídem. 
do sistema ${ }^{12}$. Por fim, nos remetendo à noção de completude, Bobbio a explicita como característica do sistema jurídico pela qual o juiz pode nele encontrar norma para solucionar qualquer caso.

Transpondo esse conceito de sistema ao Direito Internacional, reafirmamos a existência de um sistema jurídico internacional, que tem a sua unidade, coerência e completude garantidas pela aplicação dos princípios gerais, enquanto vetores axiológicos e integradores, fios condutores, linha mestras dos valores fundantes da sociedade internacional.

Não é este o entendimento preponderante no relatório da Comissão de Direito Internacional da ONU, sob a relatoria de Martti Koskeniemi, que apesar de trechos que parecem contraditórios entre si, evidenciando certa resistência de membros contrários ao avanço da perspectiva fragmentária, assume majoritariamente um discurso alarmista, "realista" e desmembrador do Direito Internacional. Em breves linhas:

The rationale for the Commission's treatment of fragmentation is that the emergence of new and special types of law, "self-contained regimes" and geographically or functionally limited treaty-systems creates problems of coherence in international law. New types of specialized law do not emerge accidentally but seek to respond to new technical and functional requirements. (...) Each rule-complex or "regime" comes with its own principles, its own form of expertise and its own "ethos", not necessarily identical to the ethos of neighbouring specialization. "Trade law" and "environmental law", for example, have highly specific objectives and rely on principles that may often point in different directions. In order for the new law to be efficient, it often includes new types of treaty clauses or practices that may not be compatible with old general law or the law of some other specialized branch. Very often new rules or regimes develop precisely in order to deviate from what was earlier provided by the general law. When such deviations or become general and frequent, the unity of the law suffers.

Such deviations should not be understood as legal-technical "mistakes". They reflect the differing pursuits and preferences that actors in a pluralistic (global) society have. In conditions of social complexity, it is pointless to insist on formal unity $(. . .)^{13}$.

Se um processo de transformação e especialização do Direito

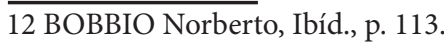

13 KOSKENNIEMI Martti (2006) Fragmentation of International Law: Difficulties arrising from the Diversification and Expansion of International Law, UN. "International Law Comission, 58a sessão. Relatório do estudo analítico realizado pelo Grupo de Estudos da Comissão de Direito Internacional, Doc. A/CN.4/L.682". 13 de abril de 2006, p. 14-15. [online] disponível em: $<$ http://untreaty.un.org/ilc/texts/1_9.html> [acessado em 21/10/2013]. 
Internacional é visível, isto é, sua normatividade tem abarcado fatos cada vez mais amplos e complexos, que exigem, portanto, a formação de ramos especializados, esses não constituem regimes, mas sub-sistemas que coexistem dentro do mesmo sistema jurídico internacional. Devemos, pois, ser cautelosos ao identificar esse fenômeno como fragmentação, já que esse vocábulo implicitamente traz um sentido negativo à expansão do Direito Internacional, ao conecta-lo à ideia de quebra e redução a fragmentos, e assim afastá-lo da noção de unidade que permeia todo o sistema internacional, e é essencial à sua caracterização como tal ${ }^{14}$.

As discussões são relevantes, de todo modo, ao chamarem atenção à situações - excepcionais, segundo investigação prática de Jonathan Charney ${ }^{15}$ - nas quais a interpretação e aplicação das normas por Cortes e Tribunais Internacionais se dá de forma fragmentada, isto é, sem levar em consideração os demais ramos especializados do Direito Internacional, bem como os precedentes dos demais tribunais. E é uma perspectiva a ser criticada, uma vez que é observada e deve ser incentivada a troca e compartilhamento de precedentes, fontes e informações entre as Cortes, fenômeno que alguns denominam de "fertilização-cruzada"16,17, ou diálogo jurisdicional ${ }^{18}$, bem como o recurso aos princípios do Direito Internacional, fontes fundantes de todo o sistema jurídico internacional.

Especificamente sobre o diálogo das fontes e sua aplicação neste contexto, como afirmação de uma perspectiva sistêmica e contrafragmentária, Alberto do Amaral Junior bem explicita sua relevância:

A pluralidade, a complexidade, a fluidez e o dinamismo se tornaram características das normas internacionais. Nesse ambiente o "diálogo" das fontes é instrumento de grande valia porque facilita a comunicação dos subsistemas entre si e com as regras gerais do direito internacional. A utilidade que proporciona reside em captar o modo de relacionamento entre normas pertencentes a subsistemas diversos segundo o princípio de coerência, que, numa era de proliferação normativa, busca conferir harmonia ao processo de aplicação do direito internacional. Consiste em recurso hermenêutico precioso para compreender a complexidade e o alcance das relações normativas surgidas a partir da expansão regulatória do direito internacional na última metade do século XX e

14 Ibídem.

15 CHARNEY Jonathan (1998) Is International Law threatened by multiple international tribunals? Recueil des Cours. Collected Courses of the Hague Academy of International Law, Vol. 271. p. 247-50.

16 AMARAL JUNIOR Alberto do (2008) "O "Diálogo" das Fontes: Fragmentação e Coerência no Direito Internacional Contemporâneo". III Anuário Brasileiro de Direito Internacional, Vol II, Belo Horizonte: CEDIN, p.11-33.

17 SANDS Philippe (1998) "Treaty, Custom and the Cross-fertilization of International Law". Yale Human Rights \& Development Law Journal, (85).

18 ROMANO Cesare (2008-2009) "Deciphering the Grammar of the International Jurisprudential Dialogue". New York University Journal of International Law \& Politics, 41. 
no limiar do século XXI (...).

O "diálogo" das fontes, que a presunção contra o conflito favorece, pressupõecompreender o direito internacional como um sistema, dotado de um repertório e de uma estrutura ${ }^{19}$.

Assim, nos filiamos aos juristas que afirmam ocorrer, diante da expansão e especialização do Direito Internacional, acompanhada da jurisdicionalização ${ }^{20}$, uma verdadeira amplificação e reafirmação da normatividade internacional e de sua institucionalização ${ }^{21}$. Se essa especialização promove um pluralismo dentro do Direito Internacional, trata-se de um pluralismo ordenado de subsistemas que coexistem, e que não desabona a unidade e a coerência desse Direito como sistema jurídico. Reafirmamos, portanto, a unidade do Direito Internacional, que passa por uma reafirmação, em todos os diferentes ramos especializados, dos fundamentos e valores essenciais da disciplina, concomitante a uma valorização do homem como sujeito e fim último do Direito Internacional ${ }^{22}$.

\section{A RELEVÂNCIA DAS CORTES E TRIBUNAIS INTERNACIONAIS PARA O SISTEMA JURÍDICO INTERNACIONAL}

A criação de Cortes e Tribunais Internacionais é aspecto inegável de transformação da realidade internacional nas últimas décadas, e deve ser entendida como resultante de razões históricas e funcionais que a subjazem. A não-exclusividade da Corte Internacional de Justiça na composição de litígios é comumente explicada com base nos principais argumentos: (i) a composição da Corte Internacional de Justiça, que não satisfaz grupos de Estados não representados; (ii) o volume de casos que assorbebaria a Corte, diante de seus recursos limitados; (iii) a ausência de conhecimento especializado, argumento significativo principalmente em áreas como direitos humanos e comérciointernacional; (iv) a falta de confiança na Corte como um fórum imparcial, especialmente por parte de Estados de recente independência ${ }^{23}$.

Simultaneamente, mudanças estruturais no Direito e nas relações Internacionais são apontadas, principalmente: (i) a erosão - ou mais corretamente a redefinição ${ }^{24}$-do conceito de soberania estatal, em favor

19 AMARAL JUNIOR Alberto do, Op. cit., p. 17-18, 20.

20 ROMANO Cesare (2009) "Can You Hear me Now? The case for extending judicial network". Chicago Journal of International Law, 10(1), p. 233-273.

21 MENEZES Wagner (2005) Ordem Global e Transnormatividade. Ijui: Ed. Unijui.

22 TRINDADE Antônio Augusto Cançado (2002) "Os Rumos do Direito Internacional Contemporâneo: de um Jus Inter Gentes a um Novo Jus Gentium no Século XXI”. In O Direito Internacional em um Mundo em Transformação. Rio de Janeiro: Renovar, p. 1039-1109.

23 FIWEW KEBEDE Tiba(2006) "What Caused the Multiplicity of International Courts and Tribunals?" Gonzaga Journal of International Law, (10).

24 SLAUGHTER Anne-Marie (2004) "Sovereignty and Power in a Networked World Order". 
O direito internacional em sua aplicação por cortes e tribunais. Camilla Capucio

de um Direito Internacional mais inclusivo, e (ii) o fim da Guerra Fria, que possibilitou um maior comprometimento dos Estados com a regra do direito, a prescindir da diplomacia orientada pelo poder que teve espaço no mundo bipolar ${ }^{25}$.

Em análise da multiplicação de órgãos judiciais internacionais, Cesare Romano esclarece que o aumento quantitativo desses órgãos veio acompanhado de uma significativa expansão e transformação de sua natureza e competência, de modo a incluir crescentes níveis de compulsoriedade em sua jurisdição e abarcar inclusive disputas que tenham entidades não estatais como parte ${ }^{26}$.

É de todo relevante nesta discussão apresentar o conceito utilizado por este autor -que resgata os critérios originariamente delineados por Christian Tomuschat- para os Órgãos Jurdiciais Internacionais, que para os fins deste trabalho são também denominados Cortes e Tribunais Internacionais, embora não seja unânime esta identificação ${ }^{27}$. O conceito envolve, portanto, cinco critérios simultâneos: (i) a permanência do órgão; (ii) o seu estabelecimento deve ter se dado através de um instrumento internacional; (iii) o recurso ao Direito Internacional como meio de decisão dos litígios; (iv) a decisão de casos deve ser feita com base em regras de procedimento preexistentes ao conflito; e (v) o resultado do processo deve ser juridicamente obrigatório.

As Cortes e Tribunais Internacionais possuem relevância crescente no sistema jurídico internacional, uma vez que são agentes institucionalizados de interpretação e aplicação do Direito Internacional, para além da vontade primária dos Estados. Seu florescimento, assim, não necessariamente possui um efeito deletério no sistema jurídico internacional, podendo constituir-se como um fenômeno de expansão da aplicação do Direito Internacional a um número maior de conflitos, ampliando o acesso à justiça e fornecendo oportunidades de desenvolvimento do Direito Internacional sem ameaçar sua legitimidade ${ }^{28}$.

O surgimento de Cortes e Tribunais internacionais deve, portanto, ser vislumbrado não como evidência de fragmentação ou compartimentarização do Direito Internacional, mas como sinal de seu amadurecimento e de prevalência do império do direito (rule of law) na sociedade internacional. A concretização judicial dos direitos

Standford Journal of International Law, 40, p. 283-327.

25 FIWEW KEBEDE, Op. cit.

26 ROMANO Cesare (1998-1999) "The proliferation of International Judicial Bodies: the pieces of the puzzle". New York University Journal of International Law \& Politics, 31, p. 710.

27 Para uma diferenciação mais precisa, e delineamento das critérios: TOMUSHAT Christan. (1987) International Courts and Tribunals with Regionally Restricted and/or Specialized Jurisdiction. Judicial Setlement of International Disputes: International Court of Justice, other Courts and Tribunals, Arbitration and Conciliation: An International Symposium. Max-Planck Institute, p. 285-416.

28 CHARNEY Jonathan, Op. cit., p. 116 
e obrigações internacionais reduz a arbitrariedade e o jogo de poder nas relações internacionais ${ }^{29}$, sendo simultaneamente a oportunidade de construção de uma verdadeira comunidade internacional.

A propósito, William W. Burke-White reconhece na realidade internacional um fenômeno de "hibridização da aplicação do Direito Internacional", citando como exemplo os Tribunais Penais Internacionais, que indicaria uma crescente fusão do direito interno e suas instituições -dentre elas principalmente as judiciais, na concreção do Direito Internacional ${ }^{30}$. A esse respeito:

Some may deem these hybrid courts as another example of the fragmentation of international criminal law. A more accurate interpretation is to see such hybrid courts as partof a system of multilevel global governance in which the national and international levels are more deeply intertwined than ever before ${ }^{31}$.

A reflexão incitada pelo autor, acerca da inegável interpenetração entre os órgãos judiciais internacionais e os órgãos judiciais internos na aplicação do Direito Internacional, como afirmação de um sistema jurídico -a caminho de um sistema jurisdicional?- internacional nos remete às discussões que se seguem, acerca da relevância desses tribunais nacionais neste sistema.

\section{A RELEVÂNCIA DOS TRIBUNAIS NACIONAIS PARA O SISTEMA JURÍDICO INTERNACIONAL}

Embora com frequência sejam ignorados em sua função de aplicação do Direito Internacional, os tribunais nacionais são elementos vitais de concretização e efetivação das normas do sistema jurídico internacional. A esse respeito, deve ser retomada a teoria da duplicação funcional (dedoublement fonctionelle) de George Scelle, que teve impacto sob a obra de inúmeros internacionalistas.

Para além das teorias do monismo e dualismo, George Scelle vislumbrava que a relação entre as esferas da normatividade interna e internacional deveria ser entendida através da utilização da capacidade funcional de agentes internos -e dentre eles os juízes internos- para assegurar a eficácia da ordem internacional. Istoé, os órgãos jurisdicionais internos se integram ao Direito Internacional face à carência orgânica deste último, sem que deixem de atuar em suas próprias competências.

29 SREENIVASA RAO Pemmaraju (2003-2004) "Multiple International Judicial Forums: a reflection of the growing strength of international law or its fragmentation?" Michigan Journal of International Law, 25, p. 958-60.

30 BURKE-WHITE William W. (2003-2004) "International Legal Pluralism". Michigan Journal of International Law, 25, p. 975-7.

31 Ibídem. 
O direito internacional em sua aplicação por cortes e tribunais. Camilla Capucio

Embora adormecida desde a década de 1930, a teoria da duplicação funcional teria nova aplicabilidade atual, em um cenário de desenvolvimento orgânico espetacular do sistema internacional, acompanhado de uma expansão dos limites e densidade normativa do Direito Internacional, em uma "mundialização do direito"32.

A atualidade de sua teoria se revela, uma vez que aos tribunais internos têm sido dadas crescentes oportunidades de desempenhar um papel substancial como instrumentos de salvaguarda da ordem jurídica internacional ${ }^{33}$. Na perspectiva de Antonio Cassese, essas oportunidades se apresentam em duas facetas. Primeiro, no caso dos tratados que concedem expressamente às partes contratantes o poder de exercitar uma jurisdição com vocação à universalidade, conferindo ao juiz nacional um poder de atuar como um órgão da sociedade internacional. Finalmente, há situações nas quais a necessidade de atuação se origina diretamente dos juízes nacionais face à inércia internacional, subrogando-se como legítimos aplicadores de normas internacionais, em tentativa de substituição à órgãos internacionais de execução coletiva e atuação como verdadeiros órgãos da sociedade internacional.

Em uma outra perspectiva, Eyal Benvenisti e George W. Downs chamam atenção para as mudanças e consequências do cenário atual no qual se encontram os juízes e cortes nacionais. Diante da já comentada jurisidicização, evidenciada pela multiplicação de Cortes e Tribunais Internacionais e ampliação de seu alcance, observa-se a atuação crescente destes órgãos jurisdicionais internacionais em temas que adentram nas competências antes reservadas ao direito interno. Assim, nesse contexto a postura dos tribunais nacionais teria se modificado "instintivamente", ou "estrategicamente", de modo a descobrirem que a maneira mais eficiente de manutenção de seu espaço interno de deliberação seria garantir que seus julgamentos sejam complementares, ao invés de conflitantes com as outras decisões nacionais e internacionais, levandoos a um tipo de "coordenação tácita". Este ímpeto por coordenação funcionaria, portanto, como um liame de evolução rumo a um sistema jurídico internacional mais coerente ${ }^{34}$.

É certo que a atuação desses juízes nacionais pode se dar de forma "individualizada", isto é, segundo a interpretação do Direito Internacional que melhor possa acomodar os interesses e escolhas nacionais ${ }^{35}$, em desconsideração de vetores de interpretação da própria ordem internacional tais como o entendimento jurisprudencial de tribunais

32 DUPUY Pierre-Marie (2007) “Unité d’Application du Droit à l'Echelle Globale et Responsabilité des Juges”. European Journal of Legal Studies, 1(2).

33 CASSESE Antonio (1990) "Remarks on Scelle's Theory of "Role Splitting" (dedoublement fonctionnel) in International Law". European Journal of International Law, 1, p. 228.

34 BENVENISTI Eyal e DOWNS George W. (2009) "National Courts, Domestic Democracy, and the Evolution of International Law". European Journal of International Law, 20, p. 61

35 BURKE-WHITE, William W., Op. cit., p. 975-7. 
internacionais e de documentos de organizações internacionais com o status de soft law.

A propósito, André de Carvalho Ramos critica a figura dos "tratados internacionais nacionais", isto é, aqueles que são interpretados e aplicados internamente não segundo parâmetros de seus intérpretes autênticos, mas segundo referências externas das Cortes nacionais ${ }^{36}$.

Yuval Shany também reconhece a evolução das recentes décadas, no incremento de participação dos órgãos jurisdicionais nacionais face ao Direito Internacional, embora vislumbre sua atuação como uma atividade crescentemente mais técnica:

a number of national courts have adopted a more international lawfriendly attitude and have started applying international law with greater frequency, in what appears to be a professional and credible manner (even in politically-charged cases involving their own governments) ${ }^{37}$.

Embora concordemos com o diagnóstico dos autores supramencionados sobre a crescente cooperação entre os órgãos jurisdicionais internos e internacionais, preferimos acreditar que esta talvez tenha se dado devido à uma paulatina mudança na auto- percepção dos juízes nacionais de seu pertencimento a um todo maior, e de suas responsabilidades enquanto tal ${ }^{38}$. Esse quadro nos permite imaginar o florescimento da governança global, e o alcance dos objetivos últimos do Direito Internacional, que devem também ser protegidos pela normatividade interna.

As responsabilidades do juiz nacional, portanto, não se limitam à cooperação com os órgãos jurisdicionais internacionais, tampouco à aplicação fática e preponderante da normatividade internacional aos fatos que lhe são apresentados internamente, mas abarca a obrigação de interpretação e concreção do Direito Internacional de maneira sólida, unitária e consistente, observando seus parâmetros autênticos de legitimidade e escapando da tentação de adequá-los aos interesses especificamente nacionais. Pressupõe-se, certamente, um grau substancial de conhecimento do sistema jurídicointernacional por parte desses agentes, e uma independência funcional interna que os possibilite exercer seu "duplo" papel evidenciado por Scelle.

36 RAMOS André de Carvalho (2011) "O Supremo Tribunal Federal e o Direito Internacional dos Direitos Humanos" In SARMENTO Daniel e SARLET Ingo Wolfgang. Direitos Fundamentais no Supremo Tribunal Federal: Balanço e Crítica. Rio de Janeiro: Ed. Lumen Juris, p. 35. (A denúncia é frequente em palestras, aulas e outros textos.)

37 SHANY Yuval (2009) "No Longer a Weak Department of Power? Reflections on the Emergence of a New International Judiciary". European Journal of International Law, 20, p. 75-6. 38 DUPUY Pierre-Marie, Op. cit. 
O direito internacional em sua aplicação por cortes e tribunais. Camilla Capucio

5. CONSIDERAÇÕES FINAIS: RUMO A UM “SISTEMA JUDICIAL INTERNACIONAL"?

Diante do exposto, há que se refletir se estaríamos caminhando rumo a um sistema jurisdicional internacional, isto é, se no interior do sistema jurídico internacional estaríamos avançando rumo à (a) um conjunto de órgãos jurisdicionais de aplicação do Direito Internacional (b) que possuem uma interação ordenada entre si e (c) com um certo grau de unidade e coesão ${ }^{39}$.

A propósito, Cesare Romano é enfático ao reconhecer certa anarquia e diferenças instransponíveis no agrupamento das Cortes e Tribunais Internacionais, que impediriam sua caracterização como um sistema judiciário internacional:

Grouping all of these bodies and mechanisms together and sub-grouping them according to a debatable taxonomy, it does not follow that an "international judicial system" exists. If by "system" it is ordinarily meant “... a regularly interacting or interdependent group of items forming a unified whole ... " or "... a functionally related group of elements..." then by all standards the bodies listed in this chart do not amount to a system $^{40}$.

Nem ao menos por isso é possível ignorar que todos os órgãos judiciais internacionais -e aqui desejamos também adicionar aqueles nacionais- apliquem em suas decisões o "corpus juris" do Direito Internacional ${ }^{41}$, e façam parte do sistema jurídico internacional como entendido anteriormente, em um todo maior de formulação, aplicação e execução do Direito Internacional. Assim, resta claro que ao reconhecermos a inexistência atual de um sistema jurisdicional internacional não estamos a desconstruir a caracterização do Direito Internacional como um sistema jurídico, mas constatando a necessidadede desenvolvimento de arcabouços normativos, teorias jurídicas, boas-práticas, e salvaguardas institucionais ${ }^{42}$, de modo a integrar de maneira "menos frouxa" as instituições jurisdicionais nacionais e internacionais, em sua função de aplicação do Direito Internacional.

Semelhantemente, Yuval Shany também reconhece inicialmente a inexistência de um judiciário internacional, ao vislumbrar os órgãos jurisdicionais internacionais como "ilhas de jurisdição", diante da incapacidade da Corte Internacional de Justiça de assumir um

39 ABI-SAAB Georges (1999) "Fragmentation or Unification: some concluding remarks". New York University Journal of International Law and Politics, 31, p. 920.

40 ROMANO Cesare, Op. cit., p. 723.

41 ROMANO Cesare, Ibíd., p.727.

42 SHANY Yuval, Op. cit., p. 91. 
papel central no orquestramento entre eles, da voluntariedade da coordenação; e, com enfoque na ausência ou rudimentariedade de regras e instrumentos de regulação de conflitos de competência entre eles ${ }^{43}$. Em trabalho posterior, contudo, amadurece a ideia de fortalecimento e emergência de um novo judiciário internacional, certamente com um caminho de construção pela frente, mas com relevante papel dos órgãos judiciários nacionais- o qual buscamos também destacar ${ }^{44}$.

Ao optarmos pela inclusão dos órgãos judiciais nacionais como elementos indispensáveis do sistema judicial internacional, reforçamos pois a necessidade de sua atuação, de seu envolvimento na aplicação deste "corpus juris" do Direito Internacional que os interconecta às Cortes e Tribunais Internacionais. É certo que isto implica distanciar o alcance ou completude deste sistema na escala evolutiva e de amadurecimento da sociedade internacional rumo à governança global, mas significa construí-lo mais consistente, concreto e acessível aos indivíduos, fim último de todo o direito enquanto evento social. Nesta esteira, merece destaque a reflexão de Wagner Menezes:

A essência do Direito está em que ele é universal, tendo no Direito Internacional o instrumento de redimensionamento desse importante papel e dos vetores axiomáticos que lhe inspiram, de maneira que, ignorá-lo significa não compreender o próprio sistema comoum todo ${ }^{45}$.

Concluímos, pois, retomando a ideia de que os aparentes argumentos da fragmentação evidenciam, em última análise a existência de um sistema jurídico único e coeso. Um sistema jurídico internacional plural -com subsistemas e tribunais especializados- permite a proteção reforçada de valores caros à evolução dos povos rumo à uma verdadeira comunidade global, e reafirma a sua universalidade, como instrumento de justiça, equidade e dignidade entre os seres humanos.

\section{REFERÊNCIAS BIBLIOGRÁFICAS}

ABI-SAAB George (1987) Cours Général de Droit International Public. Recueil des Cours. Collected Courses of the Hague Academy of International Law, 207.

ABI-SAAB Georges (1999) "Fragmentation or Unification: some concluding remarks". New York University Journal of International Law and Politics, 31.

AMARAL JUNIOR Alberto do (2008) "O "Diálogo" das Fontes: Fragmentação e Coerência no Direito Internacional Contemporâneo”.

43 SHANY Yuval (2003) The Competing Jurisdictions of International Courts and Tribunals. New York: Oxford University Press. p. 106-9.

44 SHANY Yuval, Op. cit., p. 91

45 MENEZES Wagner (2011) “Direito Internacional: Temas e perspectivas globais”. Revista Consulex, (357), p. 28. 
O direito internacional em sua aplicação por cortes e tribunais. Camilla Capucio

III Anuário Brasileiro de Direito Internacional, Vol. II. Belo Horizonte: CEDIN, p.11-33.

BENVENISTI Eyal e DOWNS George W. (2009) "National Courts, Domestic Democracy, and the Evolution of International Law". European Journal of International Law, 20.

BOBBIO Norberto (1995) Teoria do Ordenamento Jurídico. Brasília: Editora Universidade de Brasília.

BURKE-WHITE William W. (2003-2004) "International Legal Pluralism". Michigan Journal of International Law, 25.

CASSESE Antonio (1990) "Remarks on Scelle's Theory of "Role Splitting" (dedoublement fonctionnel) in International Law". European Journal of International Law, 1.

CHARNEY Jonathan (1998) Is International Law threatened by multiple international tribunals? Recueil des Cours. Collected Courses of the Hague Academy of International Law,Vol. 271.

DUPUY Pierre-Marie (2007) “Unité d'Application du Droit à l'Echelle Globale et Responsabilité des Juges". European Journal of Legal Studies, $1(2)$.

FIWEW KEBEDE Tiba (2006) "What Caused the Multiplicity of International Courts and Tribunals?" Gonzaga Journal of International Law, 10.

HART H. L. A (2009) O Conceito de Direito. São Paulo: Editora WMF Martins Fontes.

KELSEN Hans (2006) Teoria pura do direito. São Paulo: Editora WMF Martins Fontes.

KOSKENNIEMI Martti (2006) Fragmentation of International Law: Difficulties arrising from the Diversification and Expansion of International Law, UN. "International Law Comission, 58a sessão. Relatório do estudo analítico realizado pelo Grupo de Estudos da Comissão de Direito Internacional, Doc. A/CN.4/L.682”. 13 de abril de 2006, p. 14-15. [online] disponível em: <http://untreaty.un.org/ilc/ texts/1_9.html> [acessado em 21/10/2013].LOSANO Mario G. (2008) Sistema e estrutura no direito, volume I: das origens à escola histórica. São Paulo: Editora WMF Martins Fontes.

MENEZES Wagner (2005) Ordem Global e Transnormatividade. Ijui: Ed. Unijui.

MENEZES Wagner (2011) "Direito Internacional: Temas e perspectivas globais". Revista Consulex, (357).

RAMOS André de Carvalho. (2011) "O Supremo Tribunal Federal e o Direito Internacional dos Direitos Humanos.” In SARMENTO Daniel e SARLET Ingo Wolfgang. Direitos Fundamentais no Supremo Tribunal Federal: Balanço e Crítica. Rio de Janeiro: Ed. Lumen Juris.

ROMANO Cesare (1998-1999) "The proliferation of International Judicial Bodies: the pieces of the puzzle". New York University Journal of 
International Law \& Politics, 31, p. 710.

ROMANO Cesare (2008-2009) "Deciphering the Grammar of the International Jurisprudential Dialogue". New York University Journal of International Law \& Politics, 41.

ROMANO Cesare (2009) "Can You Hear me Now? The case for extending judicial network." Chicago Journal of International Law, 10(1), p. 233-273.

ROMANO Santi (2008) O ordenamento jurídico. Florianópolis: Boiteux. SANDS Philippe (1998) "Treaty, Custom and the Cross-fertilization of International Law”. Yale Human Rights \& Development Law Journal, (85). SHANY Yuval (2003) The Competing Jurisdictions of International Courts and Tribunals. New York: Oxford University Press.

SHANY Yuval (2009) "No Longer a Weak Department of Power? Reflections on the Emergence of a New International Judiciary". European Journal of International Law, 20.

SLAUGHTER Anne-Marie (2004) "Sovereignty and Power in a Networked World Order". Standford Journal of International Law, 40, p. 283-327.

SREENIVASA RAO Pemmaraju (2003-2004) "Multiple International Judicial Forums: a reflection of the growing strength of international law or its fragmentation?" Michigan Journal of International Law, 25.

TOMUSHAT Christan. (1987) International Courts and Tribunals with Regionally Restricted and/or Specialized Jurisdiction. Judicial Setlement of International Disputes: International Court of Justice, other Courts and Tribunals, Arbitration and Conciliation: An International Symposium. Max-Planck Institute, p. 285-416.

TRINDADE Antônio Augusto Cançado (2002) “Os Rumos do Direito Internacional Contemporâneo: de um Jus Inter Gentes a um Novo Jus Gentium no Século XXI". In O Direito Internacional em um Mundo em Transformação. Rio de Janeiro: Renovar, p. 1039-1109. 